\title{
PELUANG DAN TANTANGAN INTERPROFESSIONAL EDUCATION DI MASA PANDEMI COVID-19
}

\author{
Wiwik Afridah $^{1}$, Fifi Khoirul Fitriyah ${ }^{1 *}$, Silvi Puspitasari ${ }^{1}$, Edza Aria Wikurendra ${ }^{2}$, Satria \\ Wijaya $^{1}$ \\ ${ }^{1}$ Universitas Nahdlatul Ulama Surabaya, Indonesia \\ ${ }^{2}$ Szent Istvan University Kaposvar Campus, Hungaria \\ *E-mail: fifi@unusa.ac.id
}

\begin{abstract}
Health professionals are required to be ready to face challenges in the health sector (triple burden) caused by infectious diseases, degenerative diseases and emerging diseases such as Covid19 which is currently a pandemic. Health academics have a role to provide education and training for students with team-based service competencies. The research objective was to identify opportunities and challenges for interprofessional education (IPE) in the practical experiences of health faculty students. Collect data using a questionnaire and analyzed it descriptively. The results of the measurement of knowledge show that 73\% of respondents understand IPE, $94.6 \%$ of respondents understand about working with other professions through IPE. $97.0 \%$ of respondents understand IPE to train the confidence of prospective health workers. $88.0 \%$ of respondents understand IPE to provide joint services with different professions. While the measurement results obtained $92.8 \%$ of respondents agreed to the application of IPE in learning at the Faculty of Health, choosing to agree that prospective health workers must study and practice directly for $98.8 .0 \%$ by paying attention to 4 IPE factors (ethics, roles/responsibilities, interpersonal communication and teamwork, and $98.8 \%$ of respondents agreed that health services could be provided optimally if they were able to understand and appreciate the competence of each health profession, while the measurement results of IPE skills were obtained $97.0 \%$ of respondents agreed that when studying in the laboratory/field must respect different friends, $98.8 \%$ of respondents agree that students who try to be good listeners, and $56.3 \%$ of respondents who choose not to wait for orders, and $83.8 \%$ of respondents who are tasked with carrying out the correct task. It is felt that $46.7 \%$ find it difficult to use creativity when carrying out tasks when they have to work with other professions.
\end{abstract}

Keywords: Interprofessional Education, Knowledge, Attitudes, Skills

\begin{abstract}
ABSTRAK
Profesional kesehatan dituntut siap menghadapi tantangan dibidang kesehatan (triple burden) yang disebabkan penyakit infeksi, penyakit degeneratif serta penyakit emerging seperti covid-19 yang saat ini menjadi pandemi. Akademisi kesehatan memiliki peran untuk memberikan pendidikan dan pelatihan bagi mahasiswa dengan kompetensi layanan berbasis tim. Tujuan penelitian adalah mengidentifikasi peluang dan tantangan Interprofessional education (IPE) dalam pengalaman praktik mahasiswa fakultas kesehatan. Pengumpulan data menggunakan kuesioner dan dianalisis secara deskriptif. Hasil pengukuran pengetahuan menunjukkan bahwa $73 \%$ responden memahami IPE, 94,6\% responden memahami tentang bekerja sama dengan profesi lain melalui IPE. 97,0\% responden
\end{abstract}


memahami IPE untuk melatih kepercayaan diri calon tenaga kesehatan. 88,0\% responden memahami IPE untuk memberikan pelayanan bersama dengan profesi yang berbeda. Sedangkan hasil pengukuran sikap didapatkan $92,8 \%$ responden setuju pemberlakuan IPE pada pembelajaran di Fakultas Kesehatan, memilih setuju bahwa calon tenaga kesehatan wajib belajar dan praktik langsung sebesar 98,8,0\% dengan memperhatikan 4 faktor IPE (Etika, peran/ tanggung jawab, komunikasi interpersonal dan kerja tim, dan 98,8\% responden setuju bahwa layanan kesehatan dapat diberikan dengan optimal jika mampu memahami dan menghargai kompetensi dari masing-masing profesi Kesehatan. Sementara hasil pengukuran terhadap keterampilan IPE didapatkan 97,0\% responden setuju bahwa ketika belajar di laboratorium/lapangan harus menghargai pendapat teman yang berbeda, 98,8\% responden setuju bahwa mahasiswa berusaha menjadi pendengar yang baik, dan $56,3 \%$ responden memilih tidak menunggu perintah, serta $83,8 \%$ responden menyatakan mampu menyelesaikan tugas dengan benar. Sedangkan hambatan yang dirasakan yaitu 46,7\% sulit menggunakan kreativitas saat menjalankan tugas ketika harus bersama profesi lain.

Kata kunci: Interprofessional Education, Pengetahuan, Sikap, Keterampilan

\section{PENDAHULUAN}

\section{World Health Organization (WHO)} mengakui kolaborasi inter-profesional sebagai sebuah strategi inovatif saat mengatasi krisis profesional kesehatan ${ }^{(1)}$. Profesional kesehatan sebagai pelaku utama penyelenggaraan upaya kesehatan dituntut siap menghadapi tantangan dibidang kesehatan (triple burden) yang disebabkan penyakit infeksi, penyakit degeneratif serta penyakit emerging seperti covid-19 yang saat ini menjadi pandemi di dunia $^{(2)}$. IPE penting untuk mempersiapkan calon tenaga Kesehatan lebih profesional. Atas dasar pelayanan profesional semua tenaga kesehatan baik perawat, dokter, bidan, ahli gizi, ahli kesehatan masyarakat diberikan amanah untuk dapat saling berkolaborasi satu dengan yang lain ${ }^{(3)}$.

Kolaborasi inter-profesional merupakan strategi inovatif saat mengatasi krisis profesional kesehatan ${ }^{(4)}$. Masih ada hambatan yang terjadi di lapangan ketika mahasiswa belajar praktik bersama dengan profesi yang berbeda, diantara-nya belum efektifnya kolaborasi inter-profesional. Hal ini pun masih banyak terjadi di berbagai fasilitas layanan kesehatan. Untuk itu, diperlukan langkah strategis guna melatih mahasiswa memiliki kesiapan dan pemahaman tentang IPE sebelum terjun ke lapangan yang akan menjadi bekal dalam layanan kesehatan.

\section{METODE PENELITIAN}

Jenis penelitian ini adalah deskriptif. Populasi Target dengan sampel minimal 10\% dari masing-masing program studi di Fakultas Kesehatan semester 4 dan 6 yaitu pada program studi Kesehatan Masyarakat, Gizi, Analis Teknologi Laboratorium Kesehatan, dan Keselamatan dan Kesehatan Kerja. Penelitian bertujuan untuk mengidentifikasi konsep IPE dalam pengalaman praktik mahasiswa fakultas kesehatan. Pengumpulan data menggunakan kuesioner dan dianalisis secara deskriptif. 
HASIL DAN PEMBAHASAN

\section{Karakteristik responden}

Tabel 1. Distribusi Karakteristik Responden

\begin{tabular}{|c|c|c|}
\hline No Karakteristik & Frekuensi & Persentase \\
\hline \multicolumn{3}{|l|}{ Jenis Kelamin } \\
\hline Laki-laki & 9 & 5,4 \\
\hline Perempuan & 158 & 94,6 \\
\hline Total & 167 & 100,0 \\
\hline \multicolumn{3}{|l|}{ Umur } \\
\hline 1. 17-25 tahun & 160 & 95,8 \\
\hline 26-35 tahun & 7 & 4,2 \\
\hline Total & 167 & 100,0 \\
\hline \multicolumn{3}{|l|}{ Program Studi } \\
\hline $\begin{array}{ll}\text { 1. } & \text { D-IV } \\
\text { Keselamatan } \\
\text { dan Kesehatan } \\
\text { Kerja }\end{array}$ & 6 & 3,6 \\
\hline $\begin{array}{l}\text { 2. D-IV Analis } \\
\text { Kesehatan }\end{array}$ & 66 & 39,5 \\
\hline $\begin{array}{l}\text { 3. S-1 Kesehatan } \\
\text { Masyarakat }\end{array}$ & 85 & 50,9 \\
\hline S-1 Gizi & 10 & 6,0 \\
\hline Total & 167 & 100,0 \\
\hline \multicolumn{3}{|l|}{ Semester } \\
\hline 1. $\quad$ Semester 4 & 94 & 56,3 \\
\hline 2. Semester 6 & 73 & 43,7 \\
\hline Total & 167 & 100,0 \\
\hline
\end{tabular}

Wade dan Travis (2014) menjelaskan bahwa, jenis kelamin merupakan atribut-atribut fisiologis dan anatomis yang membedakan antara laki-laki dan perempuan sejak dari lahir. Berdasarkan Tabel 1 di atas, diketahui bahwa hampir seluruhnya $(94,6 \%)$ responden berjenis kelamin perempuan.

Terdapat 9 kategori pembagian umur menurut Depkes RI, yaitu mulai dari masa balita 0-5 tahun, masa kanak-kanak 5-11 tahun, masa remaja awal 12-16 tahun, masa remaja akhir 17-
25 tahun, masa dewasa awal 26-35 tahun, masa dewasa akhir 36-45 tahun, masa lansia awal 4655 tahun, masa lansia akhir 56-65 tahun, dan masa manula atas > 65 tahun (Depkes, 2009). Kategori umur pada penelitian ini dibuat berdasarkan range umur terendah sampai tertinggi. Berdasarkan Tabel 1 diketahui bahwa umur responden yang menjadi subjek penelitian hampir seluruhnya $(95,8 \%)$ dengan rentang usia 17-25 tahun.

Program studi adalah kesatuan kegiatan pendidikan dan pembelajaran yang memiliki kurikulum dan metode pembelajaran tertentu dalam satu jenis pendidikan akademik, pendidikan profesi dan atau pendidikan vokasi. Universitas Nahdlatul Ulama Surabaya memiliki empat program studi di dalam fakultas kesehatan. Berdasarkan Tabel 1 diketahui bahwa program studi responden yang mengikuti penelitian ini setengah $(50,9 \%)$ berasal dari $\mathrm{S}-1$ Kesehatan Masyarakat.

Semester merupakan istilah yang sering digunakan dalam periode tahun ajaran pendidikan. Semester merupakan penanggalan dalam bahasa Latin yang terdiri atas sex atau six (enam) dan menstrues atau mensis (bulan) yang berarti enam bulan berturut-turut. Berdasarkan Tabel 1 diketahui bahwa responden yang mengikuti penelitian ini sebagian besar $(56,3 \%)$ responden sedang menempuh pendidikan di semester 4 . 
Implementasi Interprofessional Education (IPE)

Implementasi IPE dalam kurikulum Pendidikan kesehatan memiliki tiga fokus. Pertama, peningkatan pengetahuan, keterampilan, dan sikap mahasiswa dalam praktik kolaborasi antar profesi kesehatan ${ }^{(5)}$. Berikut distribusi frekuensi responden penelitian berdasarkan pengetahuan tentang IPE.
Tabel 2. Distribusi Frekuensi Pemahaman IPE

\begin{tabular}{|c|c|c|}
\hline No. Pemahaman IPE & Frekuensi & Persentase \\
\hline Tidak Tahu & 16 & 9,6 \\
\hline Tidak & 29 & 17,4 \\
\hline $\mathrm{Ya}$ & 122 & 73,0 \\
\hline Total & 167 & 100,0 \\
\hline
\end{tabular}

Berdasarkan Tabel 1 diketahui bahwa sebagian besar $(73,0 \%)$ responden memahami tentang Interprofessional Education.

Tabel 3. Distribusi Frekuensi Pemahaman IPE Berdasarkan Program Studi

\begin{tabular}{lrrrrrrrr}
\hline \multirow{2}{*}{ Kategori } & \multicolumn{8}{c}{ Program Studi } \\
\cline { 2 - 11 } & \multicolumn{2}{c}{ D4 K3 } & \multicolumn{2}{c}{ S1 Kesmas } & \multicolumn{2}{c}{ S1 Gizi } & \multicolumn{2}{c}{ D4 Ankes } \\
\cline { 2 - 10 } & $\mathrm{n}$ & $\%$ & $\mathrm{n}$ & $\%$ & $\mathrm{n}$ & $\%$ & $\mathrm{n}$ & $\%$ \\
\hline Tidak tahu & 1 & 16.7 & 4 & 6.1 & 9 & 10.6 & 2 & 20.0 \\
\hline Tidak & 2 & 33.3 & 4 & 6.1 & 18 & 21.2 & 5 & 50.0 \\
\hline Ya & 3 & 50.0 & 58 & 87.8 & 58 & 68.2 & 3 & 30.0 \\
\hline Total & 6 & 100.0 & 66 & 100.0 & 85 & 100.0 & 10 & 100.0 \\
\hline
\end{tabular}

Distribusi frekuensi pemahaman tentang IPE berdasarkan program studi diketahui bahwa, responden pada Program Studi D4 Keselamatan dan Kesehatan Kerja dan D4 Analis kesehatan secara keseluruhan masih kurang memahami tentang IPE.

Tabel 4. Detail Implementasi Pemahaman IPE

\begin{tabular}{|c|c|c|c|}
\hline No & Kategori & Frekuensi & Persentase \\
\hline \multicolumn{4}{|c|}{$\begin{array}{l}\text { Pemahaman Kerja Sama } \\
\text { dengan Profesi Lain }\end{array}$} \\
\hline 1. & Tidak Tahu & 6 & 3,6 \\
\hline 2. & Tidak & 3 & 1,8 \\
\hline 3. & $\mathrm{Ya}$ & 158 & 94,6 \\
\hline & Total & 167 & 100,0 \\
\hline
\end{tabular}

Pemahaman IPE untuk Melatih Kepercayaan Diri

\begin{tabular}{llrr}
\hline 1. & Tidak Tahu & 5 & 3,0 \\
2. & Ya & 162 & 97,0 \\
\hline & Total & 167 & 100,0 \\
\hline
\end{tabular}

\begin{tabular}{|c|c|c|c|}
\hline No & Kategori & Frekuensi & Persentase \\
\hline \multicolumn{4}{|c|}{$\begin{array}{l}\text { Pemahaman IPE untuk Memberikan } \\
\text { Pelayanan Bersama dengan } \\
\text { Profesi Berbeda }\end{array}$} \\
\hline 1. & Tidak Tahu & 15 & 9,0 \\
\hline 2. & Tidak & 5 & 3,0 \\
\hline 3. & $\mathrm{Ya}$ & 147 & 88,0 \\
\hline & Total & 167 & 100,0 \\
\hline
\end{tabular}

Pemahaman Perlunya IPE

untuk Menghadapi Covid-19

\begin{tabular}{llrr} 
1. & Tidak Tahu & 6 & 3,6 \\
2. & Tidak & 6 & 3,6 \\
3. & Ya & 155 & 92,8 \\
\hline & Total & 167 & 100,0 \\
\hline
\end{tabular}

Berdasarkan Tabel 4 diketahui bahwa hampir seluruhnya $(94,6 \%)$ responden memahami tentang bekerja sama dengan profesi lain melalui Interprofessional Education. Hampir seluruhnya $(97,0 \%)$ responden 
memahami tentang Inter-professional Education untuk melatih kepercayaan diri calon tenaga kesehatan. Hampir seluruhnya (88,0\%) responden memahami tentang Interprofessional Education untuk memberikan pelayanan bersama dengan profesi yang berbeda. Hampir seluruhnya $(92,8 \%)$ responden setuju dengan pemberlakuan Interprofessional Education pada sistem pembelajaran di fakultas kesehatan untuk menghadapi covid-19.

\section{Interprofessional Education}

(IPE)

merupakan konsep pendidikan terintegrasi untuk peningkatan kemampuan kolaborasi. IPE dapat terjadi ketika dua atau lebih mahasiswa dari program studi kesehatan yang berbeda belajar bersama dengan tujuan untuk meningkatkan kerja sama dan kualitas pelayanan Kesehatan ${ }^{(6)}$. Menurut WHO (2013) IPE adalah segalanya tentang berusaha saling mengerti dan saling menghargai antar profesi kesehatan, dengan adanya interaksi di antara profesi yang berbeda $^{(6)}$. Keberhasilan proses pendidikan interprofesional atau IPE di perguruan tinggi tidak lepas dari peran dosen sebagai tenaga pendidik serta inisiatif mahasiswa untuk belajar bersama yang dapat terjadi jika ter fasilitasi oleh lingkungannya seperti sistem dan juga tenaga kependidikan ${ }^{(7)}$.

\section{Analisis Sikap tentang IPE}

Fokus kedua dalam implementasi IPE yaitu pada pembelajaran tentang bagaimana menciptakan kolaborasi yang efektif dalam sebuah tim $^{(5)}$. Berikut ini merupakan distribusi frekuensi responden penelitian berdasarkan sikap tentang IPE.

Tabel 5. Distribusi Frekuensi Sikap tentang IPE

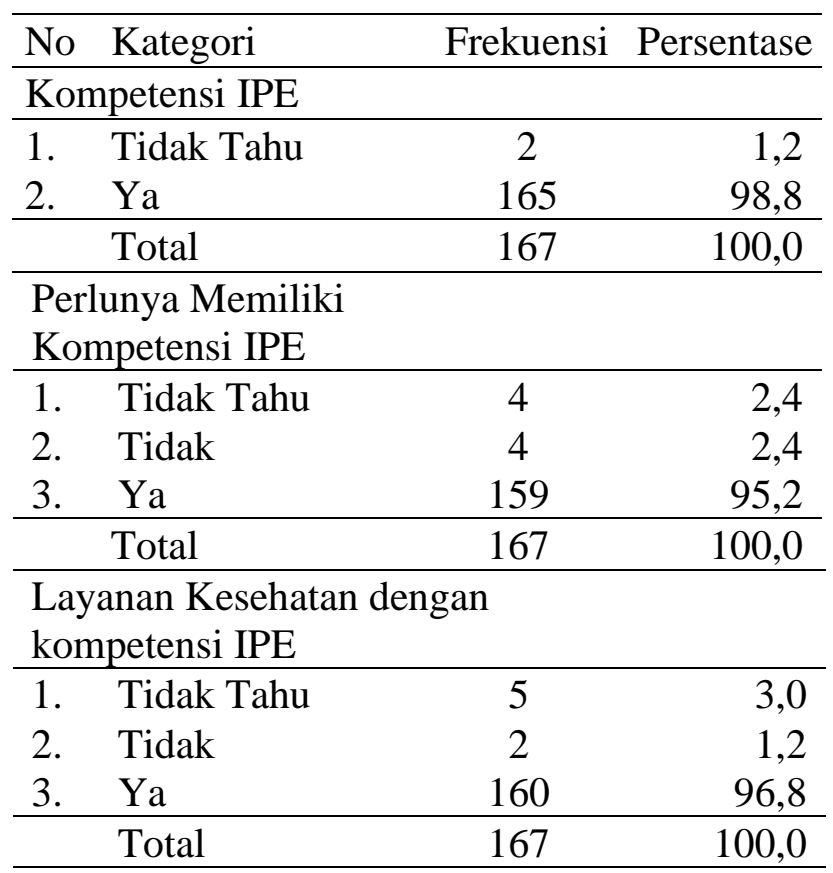

Kemampuan Memahami

dan Menghargai

\begin{tabular}{llcr}
\hline 1. & Tidak Tahu & 1 & 0,6 \\
2. & Tidak & 1 & 0,6 \\
3. & Ya & 165 & 98,8 \\
\hline & Total & 167 & 100,0 \\
\hline
\end{tabular}

Kemampuan Mengemban

Tanggung jawab

\begin{tabular}{llcr}
\hline 1. & Tidak Tahu & 7 & 4,2 \\
2. & Tidak & 1 & 0,6 \\
3. & Ya & 159 & 95,2 \\
\hline & Total & 167 & 100,0 \\
\hline
\end{tabular}

Berdasarkan Tabel 5 diketahui bahwa hampir seluruhnya $(98,8,0 \%)$ responden memilih ya atau setuju bahwa calon tenaga kesehatan wajib belajar dan praktik langsung tentang etika, peran/tanggung jawab, komunikasi interpersonal dan kerja tim. Hampir seluruhnya $(95,2 \%)$ responden memilih ya atau setuju bahwa etika, peran/tanggung jawab, komunikasi interpersonal dan kerja tim harus 
dilatih terus menerus dan langsung berhadapan dengan klien.

Pada Tabel 5 juga menunjukkan bahwa hampir seluruhnya $(96,8 \%)$ memilih ya atau setuju bahwa setiap layanan kesehatan yang diberikan selalu memperhatikan 4 faktor IPE (Etika, peran/ tanggung jawab, komunikasi interpersonal dan kerja tim). Hampir seluruhnya $(98,8 \%)$ responden memilih ya atau setuju bahwa layanan kesehatan dapat diberikan dengan optimal jika mampu memahami dan menghargai kompetensi dari masing-masing profesi Kesehatan. Di samping itu, dapat diinformasikan pula bahwa hampir seluruhnya $(95,2 \%)$ responden memilih ya atau setuju bahwa mereka mampu mengemban tanggung jawab sebagai calon tenaga kesehatan yang mahir dalam menjalankan kompetensi sesuai profesi.

Responden merasa perlu belajar dan praktik langsung tentang Etika, peran/tanggung jawab, komunikasi interpersonal dan kerja tim. Menurut Dewi, et al., (2019), dari hasil penelusuran belum ada satu pun perguruan tinggi yang telah menerapkan IPE masuk ke dalam level kurikulum. Perguruan tinggi hanya menerapkan IPE sebagai model dalam pembelajaran $^{(8)}$.

\section{Analisis keterampilan/praktik tentang IPE}

Fokus ketiga dalam implementasi IPE adalah bagaimana menciptakan kerja sama yang efektif untuk meningkatkan kualitas pelayanan terhadap pasien ${ }^{(5)}$. Berikut ini merupakan distribusi frekuensi responden penelitian berdasarkan keterampilan/praktik tentang IPE.

Tabel 6. Distribusi Frekuensi Keterampilan atau Praktik tentang IPE

\begin{tabular}{|c|c|c|c|}
\hline No & Kategori & Frekuensi & Persentase \\
\hline \multicolumn{4}{|c|}{$\begin{array}{l}\text { Kemampuan Menghargai } \\
\text { Pendapat Orang Lain }\end{array}$} \\
\hline 1. & Tidak Tahu & 4 & 2,4 \\
\hline 2. & Tidak & 1 & 0,6 \\
\hline \multirow[t]{2}{*}{3.} & $\mathrm{Ya}$ & 162 & 97,0 \\
\hline & Total & 167 & 100,0 \\
\hline \multicolumn{4}{|c|}{ Menjadi Pendengar yang Baik } \\
\hline 1. & Tidak Tahu & 2 & 1,2 \\
\hline \multirow[t]{2}{*}{3.} & Ya & 165 & 98,8 \\
\hline & Total & 167 & 100,0 \\
\hline \multicolumn{4}{|c|}{ Bekerja Menunggu Perintah } \\
\hline 1. & Tidak Tahu & 11 & 6,6 \\
\hline 2. & Tidak & 94 & 56,3 \\
\hline \multirow[t]{2}{*}{3.} & $\mathrm{Ya}$ & 62 & 37,1 \\
\hline & Total & 167 & 100,0 \\
\hline \multicolumn{4}{|c|}{ Kemampuan Menyelesaikan Tugas } \\
\hline 1. & Tidak Tahu & 20 & 12,0 \\
\hline 2. & Tidak & 7 & 4,2 \\
\hline \multirow[t]{2}{*}{3.} & $\mathrm{Ya}$ & 140 & 83,8 \\
\hline & Total & 167 & 100,0 \\
\hline \multicolumn{4}{|c|}{ Kemampuan Mengatasi Masalah } \\
\hline 1. & Tidak Tahu & 5 & 3,0 \\
\hline 2. & Tidak & 4 & 2,4 \\
\hline 3. & $\mathrm{Ya}$ & 158 & 94,6 \\
\hline & Total & 167 & 100,0 \\
\hline
\end{tabular}

Berdasarkan Tabel 6 diketahui bahwa hampir seluruhnya $(97,0 \%)$ responden memilih ya atau setuju bahwa ketika saya belajar di laboratorium (baik klinik atau lapangan), mereka menghargai pendapat teman yang berbeda. Kemudian, hampir seluruhnya $(98,8 \%)$ responden memilih ya atau setuju bahwa mereka berusaha menjadi pendengar yang baik.

Di samping itu, berdasarkan Tabel 6 diketahui bahwa sebagian besar $(56,3 \%)$ 
responden memilih tidak menunggu perintah bekerja meskipun itu pekerjaan rutin mereka lakukan. Sedangkan hampir setengah $(37,1 \%)$ responden lebih memilih menunggu perintah.

Berdasarkan Tabel 6 diketahui bahwa hampir seluruhnya $(83,8 \%)$ responden mampu menyelesaikan tugas dengan benar. Sedangkan sebagian kecil (12,0\%) responden tidak berusaha.

mengetahui mereka mampu menyelesaikan tugas dengan benar. Hampir seluruhnya $(94,6 \%)$ responden mampu bisa mengatasi masalah yang sulit jika mereka berusaha. Sementara itu, menyelesaikan tugas dengan benar, didapatkan sebesar $83,8 \%$ responden. Sebesar $94,6 \%$ responden bisa mengatasi masalah yang sulit jika

Tabel 7. Distribusi Frekuensi Bekerja Menunggu Perintah Berdasarkan Program Studi

\begin{tabular}{lrrrrrrrr}
\hline \multirow{2}{*}{ Kategori } & \multicolumn{8}{c}{ Program Studi } \\
\cline { 2 - 10 } & \multicolumn{2}{c}{ D4 K3 } & \multicolumn{2}{c}{ S1 Kesmas } & \multicolumn{2}{c}{ S1 Gizi } & \multicolumn{2}{c}{ D4 Ankes } \\
\cline { 2 - 10 } & $\mathrm{n}$ & $\%$ & $\mathrm{n}$ & \multicolumn{1}{c}{ \% } & $\mathrm{n}$ & $\%$ & $\mathrm{n}$ & $\%$ \\
\hline Tidak tahu & 1 & 16.7 & 1 & 1.5 & 7 & 8.2 & 2 & 20.0 \\
\hline Tidak & 3 & 50.0 & 44 & 66.7 & 43 & 50.6 & 4 & 40.0 \\
\hline Ya & 2 & 33.3 & 21 & 31.8 & 35 & 41.2 & 4 & 40.0 \\
\hline Total & 6 & 100.0 & 66 & 100.0 & 85 & 100.0 & 10 & 100.0 \\
\hline
\end{tabular}

Distribusi frekuensi bekerja menunggu perintah berdasarkan program studi maka diketahui bahwa, responden pada Program studi D4 K3, S1 Gizi dan D4 Analis kesehatan secara keseluruhan hampir setengahnya masih menunggu perintah untuk bekerja meskipun itu pekerjaan rutin mereka. Implementasi IPE dalam praktiknya juga membantu mahasiswa dalam peningkatan keterampilan, seperti pemecahan masalah dalam tim, konseling kesehatan, dan keterampilan klinik $^{(9)}$. Dengan adanya pembelajaran IPE bagi mahasiswa, permasalahan dapat terselesaikan jika adanya keterbukaan di dalam team work.

\section{Analisis Hambatan tentang IPE}

Setiap proses selalu memiliki hambatan, sama halnya dalam mengimplementasikan IPE dilingkungan fakultas kesehatan. Berikut distribusi frekuensi responden penelitian berdasarkan hambatan tentang IPE.

Tabel 8. Distribusi Frekuensi Hambatan tentang Pelaksanaan IPE

\begin{tabular}{|c|c|c|}
\hline No Kategori & Frekuensi & Persentase \\
\hline \multicolumn{3}{|c|}{$\begin{array}{l}\text { Antusias dalam } \\
\text { Menyelesaikan Tugas }\end{array}$} \\
\hline 1. Tidak Tahu & 5 & 3,0 \\
\hline Tidak & 9 & 5,4 \\
\hline $\mathrm{Ya}$ & 153 & 91,6 \\
\hline Total & 167 & 100,0 \\
\hline \multicolumn{3}{|c|}{ Bekerja Menunggu Instruksi } \\
\hline 1. Tidak Tahu & 8 & 4,8 \\
\hline Tidak & 74 & 44,3 \\
\hline $\mathrm{Ya}$ & 85 & 50,9 \\
\hline Total & 167 & 100,0 \\
\hline \multicolumn{3}{|c|}{ Kesulitan Menggunakan Kreativitas } \\
\hline 1. Tidak Tahu & 27 & 16,2 \\
\hline Tidak & 78 & 46,7 \\
\hline 3. $\mathrm{Ya}$ & 62 & 37,1 \\
\hline Total & 167 & 100,0 \\
\hline
\end{tabular}


No Kategori $\quad$ Frekuensi Persentase

Kemampuan Mengikuti Alur Kerja

\begin{tabular}{|c|c|c|c|}
\hline 1. & Tidak Tahu & 7 & 4,2 \\
\hline 2. & Tidak & 8 & 4,8 \\
\hline \multirow[t]{2}{*}{3.} & $\mathrm{Ya}$ & 152 & 91,0 \\
\hline & Total & 167 & 100,0 \\
\hline \multicolumn{4}{|c|}{ Kesulitan Bekerja Tim } \\
\hline 1. & Tidak Tahu & 13 & 7,8 \\
\hline 2. & Tidak & 122 & 73,1 \\
\hline & $\mathrm{Ya}$ & 32 & 19,2 \\
\hline & Total & 167 & 100,0 \\
\hline
\end{tabular}

Berdasarkan Tabel 8 diketahui bahwa hampir seluruhnya $(91,6 \%)$ responden memiliki antusias dalam menyelesaikan tugas dan setengah $(50,9 \%)$ dari responden bekerja menunggu instruksi. Sedangkan hampir setengah $(44,3 \%)$ responden bekerja tidak menunggu instruksi.
Kemudian, hampir setengah $(46,7 \%)$ responden sulit menggunakan kreativitas saat menjalankan tugas ketika harus bersama profesi lain. Sedangkan hampir setengah $(37,1 \%)$ responden tidak memiliki kesulitan dalam menggunakan kreativitas saat menjalankan tugas ketika harus bersama profesi lain.

Pada Tabel 8 juga diinformasikan bahwa pada umumnya $(91,0 \%)$ responden mengikuti alur kerja yang sudah ditetapkan. Sedangkan sebagian kecil (4,8\%) responden tidak mengikuti alur kerja yang sudah ditetapkan. Kemudian sebagian besar $(73,8 \%)$ responden tidak merasakan kesulitan dalam bekerja tim. Sedangkan sebagian kecil $(19,2 \%)$ responden merasakan kesulitan dalam bekerja tim.

Tabel 9. Tabulasi Silang Hambatan Pelaksanaan IPE Berdasarkan Program Studi

\begin{tabular}{|c|c|c|c|c|c|c|c|c|}
\hline \multirow[t]{3}{*}{ Kategori } & \multicolumn{8}{|c|}{ Program Studi } \\
\hline & \multicolumn{2}{|c|}{ D4 K3 } & \multicolumn{2}{|c|}{ S1 Kesmas } & \multicolumn{2}{|c|}{ S1 Gizi } & \multicolumn{2}{|c|}{ D4 Ankes } \\
\hline & $\mathrm{n}$ & $\%$ & $\mathrm{n}$ & $\%$ & $\mathrm{n}$ & $\%$ & $\mathrm{n}$ & $\%$ \\
\hline \multicolumn{9}{|l|}{ Bekerja Menunggu Instruksi } \\
\hline Tidak tahu & 4 & 66.7 & 2 & 3.0 & 4 & 4.7 & 2 & 20.0 \\
\hline Tidak & 0 & 0.0 & 37 & 56.1 & 31 & 36.5 & 2 & 20.0 \\
\hline $\mathrm{Ya}$ & 2 & 33.3 & 27 & 40.9 & 50 & 58.8 & 6 & 60.0 \\
\hline $\begin{array}{r}\text { Total } \\
\end{array}$ & 6 & 100.0 & 66 & 100.0 & 85 & 100.0 & 10 & 100.0 \\
\hline \multicolumn{9}{|c|}{ Kesulitan Menggunakan Kreativitas } \\
\hline Tidak tahu & 1 & 16.7 & 13 & 19.7 & 11 & 12.9 & 2 & 20.0 \\
\hline Tidak & 2 & 33.3 & 30 & 45.5 & 40 & 47.1 & 6 & 60.0 \\
\hline \multirow[t]{2}{*}{$\mathrm{Ya}$} & 3 & 50.0 & 23 & 34.8 & 34 & 40.0 & 2 & 20.0 \\
\hline & 6 & 100.0 & 66 & 100.0 & 85 & 100.0 & 10 & 100.0 \\
\hline \multicolumn{9}{|l|}{ Kesulitan Bekerja Tim } \\
\hline Tidak tahu & 0 & 0.0 & 2 & 3.0 & 8 & 9.4 & 3 & 30.0 \\
\hline Tidak & 4 & 66.7 & 50 & 75.8 & 62 & 73.0 & 6 & 60.0 \\
\hline \multirow[t]{2}{*}{$\mathrm{Ya}$} & 2 & 33.3 & 14 & 21.2 & 15 & 12.6 & 1 & 10.0 \\
\hline & 6 & 100.0 & 66 & 100.0 & 85 & 100.0 & 10 & 100.0 \\
\hline
\end{tabular}


Berdasarkan Tabel 9 dapat diinformasikan bahwa responden pada Program Studi D4 K3, S1 Gizi dan D4 Analis kesehatan secara keseluruhan setengahnya menunggu instruksi untuk bekerja. Kemudian, responden pada seluruh Program Studi secara keseluruhan setengahnya tidak tahu dan merasa kesulitan menggunakan kreativitas saat bertugas bersama profesi lain. Di samping itu, responden pada Program Studi S1 Kesmas dan S1 Gizi sebagian kecil (21.2\% dan 12.6\%) merasa kesulitan bekerja dengan tim, sedangkan Program Studi D4 Analis kesehatan hampir setengahnya (30\%) merasa tidak mengetahui kesulitan dalam bekerja tim ${ }^{(10)}$.

Setiap tenaga kesehatan memiliki peran dan kompetensi yang berbeda-beda. Batas peran yang tidak jelas antara profesional kesehatan mempersulit kolaborasi inter-profesional di

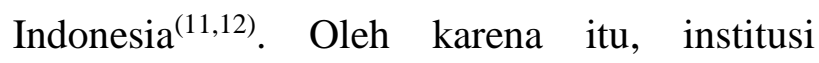
pendidikan kesehatan harus mulai mengenalkan IPE yang mampu memfasilitasi pembelajaran kolaboratif bagi seluruh mahasiswa multidisipliner.

\section{SIMPULAN DAN SARAN}

Melatih kepercayaan diri dan memberikan pelayanan bersama dengan profesi yang berbeda dengan kompetensi IPE, bisa meningkatkan keterampilan dan kinerja layanan. Setiap tenaga pengajar khususnya perlu memberikan pengalaman langsung terkait dengan IPE terutama dengan kondisi yang terjadi sekarang ini, adanya pandemi yang membutuhkan integrasi efektif dari semua pihak.

\section{REFERENSI}

1. WHO. Framework for action on interprofessional education and collaborative practice. 2013;

2. Damayanti RA, Bachtiar A. Kesiapan Mahasiswa Kesehatan terhadap Penerapan Pendidikan Interprofesional di Indonesia. Interes J Ilmu Kesehat. 2020;9(1):16-28.

3. Yusuf S. Pengembangan Model Interprofessional Education di FIK UIN Alauddin Makassar. Pengemb Model Interprofessional Educ di FIK UIN Alauddin Makassar. 2015;

4. VanKuiken, D. M., Schaefer, J. K., Flaum Hall, M., \& Browne FR. Integrating interprofessional education into the curriculum: Challenges and solutions for a university without a medical center. $\mathbf{J}$ Interprofessional Educ Pract [Internet]. 2016;2(2):5-18. Available from: https://doi.org/10.1016/j.xjep.2015.12.002

5. Sulistyowati E. Interprofessional Education (Ipe) Dalam Kurikulum Pendidikan Kesehatan Sebagai Strategi Peningkatan Kualitas Pelayanan Maternitas. J Kebidanan. 2019;8(2):123.

6. Gilbert JHV, Yan J, Hoffman SJ. A WHO report: Framework for action on interprofessional education and collaborative practice. J Allied Health. 2010;39(SUPPL. 1):196-7.

7. Dikti D, Nasional KP. HPEQ Program Sebagai Pijakan Awal Perbaikan Sistem Pendidikan. 2011.

8. Tyastuti, D., Onishi, H., Ekayanti, F., \& Kitamura K. An Educational Intervention of Interprofessional Learning in Community Based Health Care in Indonesia: What did We Learn from the Pilot Study. J Educ Pract [Internet]. 2013;4(25):1-12. Available from: https://doi.org/ISSN 2222-288X 
9. Tyastuti D, Onishi H, Ekayanti F, Kitamura $\mathrm{K}$. An Educational Intervention of Interprofessional Learning in Community Based Health Care in Indonesia: What did We Learn from the Pilot Study? J Educ Pract. 2013;4(25):1-12.

10. Arikunto. Metode Penelitian Kualitatif. Jakarta: Sagung Seto; 2005.

11. Lestari, E., Stalmeijer, R. E., Widyandana, D., \& Scherpbier A. Understanding students ' readiness for interprofessional learning in an Asian context: a mixed-methods study. BMC Med Educ. 2016;1-12.

12. Yusuf S. Pengembangan Model Interprofessional Education di FIK UIN Alauddin Makassar. Pengembangan Model Interprofessional Education Di FIK UIN Alauddin Makassar. 2015; 